\title{
Everolimus-eluting stent platforms in percutaneous coronary intervention: comparative effectiveness and outcomes
}

REVIEW

This article was published in the following Dove Press journal:

Medical Devices: Evidence and Research

24 July 2015

Number of times this article has been viewed

\section{Vasileios F Panoulas' \\ loannis Mastoris ${ }^{2}$ \\ Klio Konstantinou' \\ Maurizio Tespili ${ }^{3}$ \\ Alfonso lelasi ${ }^{3}$}

'National Heart and Lung Institute, Imperial College London, London, UK; ${ }^{2}$ Interventional Cardiovascular Research and Clinical Trials, The Zena and Michael A Wiener Cardiovascular Institute, The Icahn School of Medicine at Mount Sinai, New York NY, USA; ${ }^{3}$ Cardiology Department, Bolognini Hospital Seriate, Seriate (BG), Italy
Correspondence: Alfonso lelasi Cardiology Department, Bolognini Hospital Seriate, Via Paderno 2I, 24068 Seriate (BG), Italy

Tel +390353063628

$\mathrm{Fax}+390353063535$

Email alielasi@hotmail.com
Abstract: Despite the remarkable benefits obtained following the introduction of the first-generation drug-eluting stent (DES), concerns were raised over its long-term safety, particularly with regard to very late (beyond 1 year) stent thrombosis. Newer-generation DESs have been developed to overcome this limitation using novel stent platforms, new drugs, more biocompatible durable polymers, and bioabsorbable polymers or backbones. To date, newgeneration DESs have virtually replaced the use of first-generation DESs worldwide. In this review article, we discuss in detail the design, pharmacology, and mechanism of action of the newer-generation permanent and bioresorbable everolimus-eluting platforms. Furthermore, we present and evaluate the current evidence on the performance and safety of these devices compared to those of other available stent platforms.

Keywords: PCI, angioplasty, stent, outcome

\section{Introduction}

Percutaneous coronary intervention (PCI) has revolutionized the treatment of obstructive coronary atherosclerotic disease. Since the first case of PCI performed by Gruentzig in 1977, it has become one of the commonest procedures in medicine. ${ }^{1}$ Despite the initial favorable outcomes, plain old balloon angioplasty (POBA) was limited by frequently occurring procedural complications, including vessel dissection, restenosis, recoil, and thrombosis. The most fearsome complication, however, was abrupt vessel closure, secondary to acute elastic recoil and plaque dissection at the site of intervention. ${ }^{2}$ In 1978, Julio Palmaz developed the concept of a metal sleeve that could be placed on top of the balloon, carried to the site, and deployed by balloon expansion to support the walls of the artery, thus preventing recoil and lumen impairment. The first-in-human case to receive a Palmaz stent was reported from Sao Paulo, Brazil, in December 1987, and 7 years later, the first randomized trials demonstrated reduced revascularization and lower rates of restenosis at 6-month follow-up in the bare-metal stent (BMS) group compared to the POBA group. ${ }^{3,4}$

In 2002-2003, the regulatory authorities in Europe and the USA approved drugeluting stents (DESs) after landmark trials demonstrated significant reduction of restenosis compared with BMSs. ${ }^{5}$ The three fundamental stent components include the stent platform, the polymer, and the antiproliferative drug. The paclitaxel (TAXUS; Boston Scientific, Natick, MA, USA) and sirolimus (Cypher; Cordis, Johnson and Johnson Company, Warren, NJ, USA)-eluting stents (PESs and SESs, respectively) were the first DESs to be widely used. PES comprised a 316L stainless steel scaffold coated with a nonerodible biocompatible polyolefin matrix containing paclitaxel, 
an antimitotic microtubule inhibitor that halts cell division in neoplastic diseases. The SES was also made of $316 \mathrm{~L}$ stainless steel and a permanent nonerodible polymer that was eluting sirolimus, a macrocyclic lactone produced by Streptomyces hygroscopicus, used in renal transplantation as immunosuppressant. Despite their widespread application, delayed healing and hypersensitivity reactions have been described in human postmortem examinations with both stents. ${ }^{6}$ In an attempt to increase their radial strength, these first-generation platforms were characterized by increased strut thickness $(\sim 150 \mu \mathrm{m})$ and width, thus reducing their flexibility and conformability. As a consequence, implantation of longer stents in distal lesions and tortuous vessels was a particularly challenging task. Stent fractures were also not an uncommon encounter, particularly when these firstgeneration stents were implanted at flexing points.

\section{Design, pharmacology, and mechanism of action of everolimus-eluting stent platforms}

\section{Stent platform}

Notable developments in stent platforms, including design, structure, and material composition, have resulted in major technical advances and associated beneficial clinical outcomes. The ideal stent characteristics include 1) good deliverability; 2) excellent conformability - the stent can adopt the curvature of the vessel; 3) increased radiopacity, which enables optimal implantation of overlapping stents and optimal stent positioning (particularly when treating bifurcations or ostial lesions); 4) high radial strength to prevent reflex vascular recoil; and 5) thin-strutted structure, which reduces vascular injury and minimizes the risk for late or very late stent thrombosis (ST). ${ }^{7}$ Bioresorbable polymers or even whole-stent platforms are desirable as, in theory, would eliminate very late ST and restore vasomotion while providing temporary vessel scaffolding to prevent recoil. ${ }^{8}$

The use of cobalt-chromium ( $\mathrm{CoCr}$ ) alloys in the formation of stent platforms (Xience-Vision and Multilink 8 platforms; Abbott Vascular, Santa Clara, CA, USA) allowed the reduction in strut thickness to 80-90 $\mu \mathrm{m}$, with modest improvement in radiopacity and conformability. The increased elastic properties of $\mathrm{CoCr}$, however, occur at a cost of greater recoil when compared with $316 \mathrm{~L}$ stainless steel stents. ${ }^{9}$ Platinum-chromium (PtCr) alloys, consisting of at least $33 \%$ platinum $(\mathrm{Pt})$, represent an attractive alternative compound given their unique properties, including biocompatibility, radiopacity, chemical stability, corrosion resistance, and radial strength. The amalgamation of chromium $(\mathrm{Cr})$ and Pt in a single alloy compound, as in the Element/Omega and Promus Premier (Boston Scientific) stent platforms, ${ }^{10-12}$ yielded a significant increase in radial strength and durability, allowing a subsequent reduction in strut thickness (down to $74 \mu \mathrm{m}$ in the SYNERGY stent) while maintaining radial strength and providing improved radiopacity compared to stainless steel and CoCr alloys. ${ }^{9}$

Contrary to the Xience and the Promus stents, the Absorb everolimus-eluting platform (Abbott Vascular) comprises a bioresorbable scaffold (BRS) that enables vasomotion, expansive remodeling, and restoration of the vessel lumen after the dissolution of the scaffold. The scaffold consists mainly of poly-L-lactic acid (PLLA), which disappears with hydrolysis within 3 years after implantation. The scaffold coating is also bioresorbable, consisting of a 1:1 mixture of an amorphous matrix of poly-D,L-lactide and the antiproliferative drug everolimus. Because the PLLA lacks radiopaque properties, a pair of radiopaque Pt markers was placed at the proximal and distal ends of the scaffold. ${ }^{13}$

\section{Everolimus as antiproliferative agent: mechanism of action}

In-stent restenosis (ISR) represents the main limitation of BMSs and is secondary to neointimal hyperplasia occurring in response to local arterial injury from the PCI. Balloonand stent-related arterial wall injury initiates a cascade of vascular healing, which includes activation, proliferation, and migration of vascular smooth muscle cells, as well as increased production of extracellular matrix components. ${ }^{14}$ The presence of a foreign body, as the stent struts, prompts an excessive healing response, resulting in neointimal hyperplasia. Therefore, antiproliferative agents that safely inhibit vascular smooth muscle cell proliferation underlie the rationale and goal of DESs currently used in clinical practice. ${ }^{15}$ Two classes of antiproliferative agents have proven successful in preventing neointimal hyperplasia and ISR: paclitaxel and the rapamycin analogs (including sirolimus, everolimus, zotarolimus, and biolimus). In addition to their antiproliferative properties, these agents have different properties (eg, hydrophilicity), which may affect their clinical efficacy. For the purposes of our review, we will only focus our description on everolimus, a rapamycin analog.

Everolimus (SDZ-RAD) is a synthetic analog of sirolimus (40-O-(2-hydroethyl)-rapamycin), which was initially developed to inhibit rejection of transplanted organs. The FK506-binding protein/rapamycin complex binds to a specific cell cycle-regulatory protein, the mammalian target of rapamycin (mTOR), and inhibits its activation. TOR is a 
member of the phosphatidylinositol 3-kinase-related protein kinase family, which is involved with critical steps of the cell cycle, including checkpoints that govern DNA damage and repair. ${ }^{16}$ mTOR phosphorylates the phosphorylated heat-stable and acid-stable protein (Phas-1), which is a translational repressor that binds to eukaryotic translation initiation factor-4E-Bbnding protein-1 (eIF4EBP1). This process releases the eukaryotic initiation factor eIF4F for initiation of protein translation. mTOR also stimulates p70s6k mitogen-stimulated kinase, which promotes cell cycle protein synthesis. ${ }^{15}$ Everolimus acts as an inhibitor of cellular proliferation, intervening at the late $\mathrm{G} 1$ phase of the cell cycle and preventing the cells from entering the $S$ (proliferation) phase. ${ }^{17}$ Thus, its immunosuppressive potential relies on preventing lymphocyte and smooth muscle cell proliferation mediated by inflammatory cytokines and growth factors. To date, it has been successfully used in combination with multiple drugs to prevent rejection in heart transplant recipients and in reduction of the severity and incidence of cardiac allograft vasculopathy. ${ }^{18}$ A stentbased delivery of everolimus was found to selectively clear macrophages in rabbit atherosclerotic plaques by autophagy, an mTOR inhibition-dependent and novel mechanism to induce cell death in mammalian cells. ${ }^{19}$ Due to its molecular and chemical structure, the lipophilic properties of everolimus are increased compared to sirolimus, leading to a more rapid absorption into the arterial wall. ${ }^{20}$

\section{Kinetics of drug release}

Local delivery, modulated release, and absorption of everolimus by the arterial wall are key steps in the inhibition of neointimal hyperplasia. Drug release kinetics is a critical component of device efficacy and safety in terms of preventing recurrent adverse events. Invariably, antiproliferative agents are coupled to a matrix polymer that acts as a reservoir to ensure uniform distribution and drug retention during deployment. The polymer type, composition, and design define the kinetics of drug release following stent implantation for a period that ranges from weeks to months. First-generation DESs contained synthetic nonresorbable (permanent or durable) polymers, such as poly- $n$-butyl methacrylate and polyethylene vinyl acetate with sirolimus and a poly(styrene-b-isobutylene-b-styrene) copolymer with paclitaxel, ${ }^{21}$ which were subsequently associated with adverse allergic reactions, delayed healing, and incomplete endothelialization, thus increasing the risk for late and very late ST compared to BMSs. ${ }^{22-24}$ Hence, research has been directed toward the modification of polymers aiming at improvement of long-term DES safety. The target of further development has been 1) the reduction of the total polymer mass on the stent (eg, polymer thickness of $12.6 \mu \mathrm{m}$ for the first-generation Cypher vs 7.0 $\mu \mathrm{m}$ for the Promus Element vs $4 \mu \mathrm{m}$ for the SYNERGY, with no polymer for the Cre8); 2) selective application of the polymer on the abluminal stent area, which allows rapid endothelialization of the luminal segment, avoiding excessive neointimal proliferation on the abluminal side; 3 ) increased biocompatibility and the advent of an everolimus-eluting stent (EES) with bioresorbable polymer (SYNERGY stent, Boston Scientific); Table 1 shows the comparison of different commercially available EES platforms.

Table I Comparison of different commercially available everolimus-eluting stents

\begin{tabular}{|c|c|c|c|c|c|c|}
\hline Stents & Xience V & $\begin{array}{l}\text { Xience PRIME/ } \\
\text { Xience Xpedition }\end{array}$ & Promus Element & Promus Premier & SYNERGY & Absorb \\
\hline Stent platform & Vision: $\mathrm{CoCr}$ & Multilink-8: CoCr & Element: $\mathrm{PtCr}$ & $\begin{array}{l}\text { Promus Premier: } \\
\mathrm{PtCr}\end{array}$ & Element: $\mathrm{PtCr}$ & $\begin{array}{l}\text { PLLA, based on } \\
\text { Multilink-8 }\end{array}$ \\
\hline Strut thickness & $81 \mu \mathrm{m}$ & $81 \mu \mathrm{m}$ & $81 \mu \mathrm{m}$ & $81 \mu \mathrm{m}$ & $74 \mu \mathrm{m}$ & $158 \mu \mathrm{m}$ \\
\hline $\begin{array}{l}\text { Connectors } \\
\text { between hoops }\end{array}$ & 3 & 3 & 2 & $\begin{array}{l}2 \text { ( } 4 \text { between the } \\
3 \text { proximal hoops) }\end{array}$ & 2 & 3 \\
\hline Polymer & $\begin{array}{l}\text { Primer layer } \\
\text { PBMA } \\
\text { Drug matrix layer } \\
\text { A semicrystalline } \\
\text { random copolymer: } \\
\text { PVDF-HFP }\end{array}$ & $\begin{array}{l}\text { Primer layer } \\
\text { PBMA } \\
\text { Drug matrix layer } \\
\text { A semicrystalline } \\
\text { random copolymer: } \\
\text { PVDF-HFP }\end{array}$ & $\begin{array}{l}\text { Primer layer } \\
\text { PBMA } \\
\text { Drug matrix layer } \\
\text { A semicrystalline } \\
\text { random copolymer: } \\
\text { PVDF-HFP }\end{array}$ & $\begin{array}{l}\text { Primer layer } \\
\text { PBMA } \\
\text { Drug matrix layer } \\
\text { A semicrystalline } \\
\text { random copolymer: } \\
\text { PVDF-HFP }\end{array}$ & PLGA & PDLLA \\
\hline Manufacturer & $\begin{array}{l}\text { Abbott Vascular, } \\
\text { Santa Clara, CA, } \\
\text { USA }\end{array}$ & $\begin{array}{l}\text { Abbott Vascular, } \\
\text { Santa Clara, CA, } \\
\text { USA }\end{array}$ & $\begin{array}{l}\text { Boston Scientific, } \\
\text { Natick, MA, USA }\end{array}$ & $\begin{array}{l}\text { Boston Scientific, } \\
\text { Natick, MA, USA }\end{array}$ & $\begin{array}{l}\text { Boston Scientific, } \\
\text { Natick, MA, USA }\end{array}$ & $\begin{array}{l}\text { Abbott Vascular, } \\
\text { Santa Clara, } \\
\text { CA, USA }\end{array}$ \\
\hline
\end{tabular}

Abbreviations: CoCr, cobalt-chromium; PBMA, poly(n-butyl methacrylate); PDLLA, Poly D, L lactide; PLGA, poly(D,L-lactide-co-glycolide); PLLA, poly-L-lactic acid; PtCr, platinum-chromium; PVDF-HFP, poly(vinylidene fluoride-co-hexafluoropropylene). 


\section{Comparative efficacy and safety of EESs \\ Preclinical trials}

Everolimus has been effective in reducing neointimal hyperplasia in a rabbit's iliac artery model when administered orally. ${ }^{25}$ After implantation of a Vision BMS, oral everolimus $(1.5 \mathrm{mg} / \mathrm{kg}$ the day before, followed by $0.75 \mathrm{mg} / \mathrm{kg} / \mathrm{day}$ for 28 days) reduced neointimal thickness from $0.12 \pm 0.03 \mathrm{~mm}$ to $0.07 \pm 0.03 \mathrm{~mm}(P=0.005)$. After 28 days, $86.7 \%$ of the luminal stent surface was endothelialized in the everolimustreated animals $(96.8 \%$ in the control ones, $P<0.006){ }^{26}$ Similar results were observed after 28 days in a porcine model comparing the EES with the Multi-link Vision BMS and the Cypher SES. Results were similar between EES and SES. ${ }^{25}$

\section{BMSs versus EESs}

Everolimus has been previously tested in the PLLA-coated stainless steel S-stent (Biosensors International, Singapore), which was effective in the first human experience with EES stents for the treatment of coronary lesions (FUTURE I Trial) of 42 patients randomized in a 2:1 analogy to EES ( $n=27)$ vs BMS ( $\mathrm{n}=15)$. Patients with recent myocardial infarction (MI), diabetes, left main coronary artery disease, ostial lesions, bifurcation lesions, or presence of thrombus were excluded. The 6-month late lumen loss (LLL) was significantly reduced in the EES group; EES: $0.10 \mathrm{~mm}$ vs BMS: $0.85 \mathrm{~mm}$ $(P<0.001) .{ }^{27,28}$ There was a $70 \%$ release of the $197 \mu \mathrm{g} / \mathrm{cm}^{2}$ everolimus within 30 days and $85 \%$ within 90 days. A pooled analysis of 106 patients enrolled in both FUTURE I and its expanded sequel FUTURE II clinical trials demonstrated the beneficial effect of EES regardless of vessel size. ${ }^{29}$

In the SPIRIT I trial, which was the first-in-human study of the CoCr EES (Xience V), 60 people in nine centers in Europe were randomly assigned to either Multi-link Vision BMS $(n=32)$ or Xience V EES $(n=28) .{ }^{30}$ The study included patients with either unstable angina or silent ischemia presenting with a single de novo significant lesion (50\%-99\%), in vessels with a reference diameter of $3.0 \mathrm{~mm}$ that could be covered by a single stent of $18 \mathrm{~mm}$ length. Patients with ongoing MI, unprotected left main coronary artery disease, ostial lesions, lesions within $2 \mathrm{~mm}$ from a bifurcation, moderate-to-severe calcification, angiographically visible thrombus, and left ventricular ejection fraction (LVEF) $<30 \%$ were excluded. At 6 months follow-up, LLL $(0.10 \pm 0.21 \mathrm{~mm}$ vs $0.87 \pm 0.37 \mathrm{~mm}$, $P<0.001$ ), diameter stenosis ( $16 \pm 8 \%$ vs $39 \pm 14 \%, P<0.001$ ), and binary angiographic stenosis $(0 \%$ vs $25.9 \%, P<0.05)$ were all reduced within the EES group. ${ }^{30-32}$ At 6 months and
2 years,${ }^{32}$ there were no statistically significant differences in clinical outcomes, although the study was only powered for angiographic outcomes. No cases of ST were observed.

More recently, in the Xience or Vision Stents for the Management of Angina in the Elderly (XIMA) multicenter randomized trial, ${ }^{33}$ a total of 800 patients were randomized to BMS $(n=401)$ or EES $(n=399)$ for treatment of stable angina $(32 \%)$ or acute coronary syndrome (ACS) (68\%). Rates of dual antiplatelet therapy (DAT) at 1 year were $32.2 \%$ for patients in the BMS group and $94.0 \%$ for patients in the EES group. The primary end point occurred in $18.7 \%$ of patients in the BMS group versus $14.3 \%$ of patients in the EES group $(P=0.09)$. There was no difference in all-cause mortality (7.2\% vs $8.5 \% ; P=0.50)$, major hemorrhage ( $1.7 \%$ vs $2.3 \%$; $P=0.61)$, or cerebrovascular accident $(1.2 \%$ vs $1.5 \% ; P=0.77)$. MI $(8.7 \%$ vs $4.3 \% ; P=0.01)$ and target vessel revascularization (TVR, $7.0 \%$ vs $2.0 \% ; P=0.001$ ) occurred more often in patients in the BMS group. The randomized Everolimus-Eluting Stents Versus Bare-Metal Stents in ST-Segment Elevation Myocardial Infarction (EXAMINATION) trial, ${ }^{34}$ comparing 1,498 ST-elevation MI (STEMI) patients receiving either EES $(\mathrm{n}=751)$ or BMS $(\mathrm{n}=747)$, demonstrated significantly lower rates of target lesion revascularization (TLR; $2.9 \%$ vs $5.6 \%$; $P=0.009)$ and definite ST $(0.8 \%$ vs $2.1 \% ; P=0.03)$ at 2 years in the EES group versus the BMS group. In the BAsel Stent Kosten Effektivitäts Trial PROspective Validation Examination (BASKET-PROVE) multicenter, randomized trial, ${ }^{35} 2,314$ patients, with lesions needing stents at least $3.0 \mathrm{~mm}$ in diameter, were randomly assigned to receive CoCr EES (Xience V, $n=774$ ), SES (Cypher Select, $n=775$ ), or the CoCr (Vision, $\mathrm{n}=765)$ BMS. At 2 years of follow-up, no significant differences in cardiac death or nonfatal MI were observed with EES (2.6\%), SES (3.2\%), and BMS (4.8\%) $\left(P_{\text {logrank }}=0.06\right)$. TVR was similar between EES and SES groups but significantly lower than in the BMS group (EES: 3.1\%, SES: 3.7\%, BMS: $\left.8.9 \% ; P_{\text {logrank }}<0.001\right)$. Ergo, the EES proved to be beneficial, even in high-caliber arteries with low rates of restenosis after bare-metal stenting. The superiority of EES over BMS was also shown in a recent meta-analysis, ${ }^{36}$ which showed hazard ratios (HRs) of 0.67 (0.49-0.91), 0.71 (0.55-0.92), $0.42(0.22-0.78)$, and $0.29(0.20-0.42)$ for cardiac death, MI, definite ST, and TVR, respectively.

\section{EESs versus PESs}

The SPIRIT II trial was a multicenter, multinational trial that was conducted in 28 centers of Europe, India, and New Zealand. The trial randomized 300 patients in a 3:1 ratio to Xience V EES $(n=223)$ vs Taxus PES $(n=77)$. The primary end point was once 
again angiographically defined LLL at 6-month follow-up. In contrast to the SPIRIT I trial, the protocol of the study was not as restrictive, allowing for patients with more complex disease to be included: patients could present with two separate de novo lesions in two different vessels with reference vessel diameters ranging between $2.5 \mathrm{~mm}$ and $4.25 \mathrm{~mm}$, whereas the maximum lesion length was not to exceed $28 \mathrm{~mm}$. Once again, patients presenting with acute MI, LVEF $<30 \%$, aorto-ostial or left main coronary artery lesions, heavy calcifications, and visible thrombus in the angiogram were excluded from the study. ${ }^{37}$ The trial was powered to demonstrate noninferiority of EES relative to PES. At 6 months, the in-stent LLL was $0.11 \pm 0.27 \mathrm{~mm}$ in the EES arm, as compared to $0.36 \pm 0.39 \mathrm{~mm}$ in the PES arm $(P<0.001) .{ }^{37}$ The 5-year clinical follow-up was completed in 244 patients $(81 \%) .{ }^{38}$ At 5 -year follow-up, $19.5 \%$ of patients were on thienopyridine in the EES arm, compared to $30.5 \%$ in the PES arm. Cardiac mortality was significantly lower in the EES group than in the PES group (1.5\% vs $7.3 \%$; $P=0.015)$. There was a trend toward lower cardiac death and MI (4.8\% vs $11.4 \%$ ) and lower ischemia-driven (ID) TLR (ID-TLR; $4.7 \%$ vs $9.4 \%$ ) with EES than with PES. Hence, there was a reduction in ID major adverse cardiovascular events (MACEs) for EES vs PES (ID-MACE: $8.0 \%$ vs $18.1 \%$; $P=0.018$ ). In addition, the Academic Research Consortium-defined ST rate was numerically lower in the EES group compared to the PES group $(0.9 \%$ vs $2.8 \%)$.

The SPIRIT III trial ${ }^{39,40}$ was exclusively conducted in US centers, enrolling 1,002 patients, randomized in a 2:1 ratio into the EES study group (Xience $\mathrm{V}, \mathrm{n}=669$ ) vs PES group (Taxus, $n=333$ ). The inclusion criteria were similar to those of SPIRIT II. Similarly, the primary end point was mainly angiographic, namely LLL at 8 months, which was significantly less in the EES group compared with that in the PES group $(0.14 \pm 0.41 \mathrm{~mm}$ vs $0.28 \pm 0.48 \mathrm{~mm} ; P=0.004)$. EES was noninferior to PES with regard to target vessel failure (TVF) at 9 months $\left(7.2 \%\right.$ vs $9.0 \%$, respectively; $\left.P_{\text {noninferiority }}<0.001\right)$. At 5 years, ${ }^{40}$ TVF was reduced in the EES group (19.3\% vs $24.5 \% ; P=0.05)$. Furthermore, MACEs were significantly reduced among patients treated with EES vs those on PES at 9 months $(4.6 \%$ vs $8.1 \% ; P=0.03), 1$ year $(6.0 \%$ vs 10.3 ; $P=0.02)$, and 5 years $(13.2 \%$ vs $20.7 \% ; P=0.007)$, due to the occurrence of fewer MIs and TLRs.

In the large SPIRIT IV trial, ${ }^{41} 3,687$ patients with stable coronary artery disease were enrolled. Patients underwent PCI for up to three distinct lesions. SPIRIT IV was a pivotal study for US Food and Drug Administration approval of the EES, which randomly assigned patients to receive either EES or PES. Despite the broader inclusion criteria than studies for first-generation DES approval, patients with ACSs, visible thrombus, chronic occlusions, vein graft lesions, and true bifurcation lesions were excluded. At 1 year, the primary end point target lesion failure (TLF), defined as a composite of cardiac death, target vessel MI, or ID-TLR, was significantly lower with EES than with PES (3.9\% vs 6.6\%; $P<0.001)$. Rates of postprocedure adverse events, such as ST ( $0.3 \%$ vs $1.1 \% ; P=0.003)$, MI ( $1.9 \%$ vs $3.1 \% ; P=0.02)$, and TLR $(2.3 \%$ vs $4.5 \% ; P<0.001)$, were also lower with EES than with PES. Of interest, in a subgroup analysis of diabetic patients, no significant difference was observed in 1-year TLF rates $(6.4 \%$ vs $6.9 \% ; P=0.080)$, suggesting that the mechanisms of restenosis or the response to antiproliferative agents may vary in diabetic patients. The 3-year follow-up results of the SPIRIT IV study were particularly encouraging because they demonstrated sustained reductions in TLF, MI, and ST in the EES arm. ${ }^{42}$ More importantly, at 3 years, both all-cause mortality $(3.2 \%$ vs $5.1 \% ; P=0.02)$ and the composite of death/MI $(5.9 \%$ vs $9.1 \% ; P=0.001)$ were reduced with EES compared to the outcomes with PES use.

The SPIRIT trials were subsequently complemented by the All-comers Everolimus-Eluting Stents and PaclitaxelEluting Stents for Coronary Revascularization in Daily Practice (COMPARE) trial, ${ }^{43}$ which enrolled 1,800 patients who were subsequently randomly assigned to EES $(n=897$, Xience V) vs PES ( $n=903$, Taxus Liberté). The primary end point, MACE, defined as a composite of death, MI, or TVR was lower with EES compared with PES at 1 year $(6.2 \%$ vs $9.1 \% ; P=0.02)$, equally driven by reductions in ST $(0.7 \%$ vs $2.6 \% ; P=0.002)$, MI ( $2.8 \%$ vs $5.4 \% ; P=0.007)$, and TLR $(1.7 \%$ vs $4.8 \% ; P<0.001) .{ }^{43,44}$ The EES group maintained the significantly reduced MACE rates at 2-year follow up ( $9 \%$ vs $13.7 \% ; P=0.002$ ).

\section{EESs versus zotarolimus-eluting stents}

In the 2-year follow up of the The Real-World Endeavor Resolute Versus Xience V Drug-Eluting Stent Study in Twente (TWENTE) trial, ${ }^{45}$ a randomized study assigning allcomers to zotarolimus-eluting stent (ZES; Endeavor Resolute; Medtronic Vascular, Santa Rosa, CA, USA; n=697) vs EES (Xience $\mathrm{V}, \mathrm{n}=694$ ), there was no significant difference in the composite end point of TVF (cardiac death, target vessel MI, or TVR) in the two groups (ZES $10.5 \%$ vs EES 9.8\%; $P=0.65)$, although there were fewer TLRs in the EES group (ZES $2.6 \%$ vs EES $4.9 \% ; P=0.03$ ). Of note, only $5.4 \%$ of patients were still on DAT past the first 12 months.

In the DUTCH PEERS ${ }^{46}$ multicenter, randomized study in the Netherlands, 1,811 all-comer patients were randomly 
assigned in a 1:1 ratio to receive either CoCr ZES (Resolute Integrity; Medtronic) or PtCr EES (Promus Element; Boston Scientific). The primary end point of TVF was a composite of safety (cardiac death or target vessel-related MI) and efficacy (TVR) at 12 months, analyzed by intention to treat (with a noninferiority margin of 3\%-6\%). The primary end point occurred in $55(6 \%)$ of 905 patients in the ZES group and $47(5 \%)$ of 905 in the EES group $\left(P_{\text {noninferiority }}=0.006\right)$. We noted no significant between-group differences in individual components of the primary end point. Definite ST occurred in three $(0.3 \%)$ patients in the ZES group and six $(0.7 \%)$ patients in the EES group $(P=0.34)$. Longitudinal stent deformation was seen only in the Promus Element EES group (9 $[1.0 \%]$ of 905 EES patients vs 0 of 905 ZES patients; $P=0.002$; nine of 1,591 [0.6\%] EESs implanted became deformed), but this was not associated with any adverse events.

In another multicenter Randomized Comparison of a Zotarolimus-Eluting Stent With an Everolimus-Eluting Stent for Percutaneous Coronary Intervention (RESOLUTE Allcomers) noninferiority all-comers (excluding only STEMI) trial, Serruys et al ${ }^{17}$ demonstrated no difference in 12-month TLF (cardiac death, target vessel MI, TLR) in 2,992 patients, with $66.3 \%$ off-label indications, randomized to either ZES $(n=1,140)$ or EES $(n=1,152)$ PCI (ZES: $8.2 \%$, EES: $8.3 \%$; $\left.P_{\text {noninferiority }}<0.001\right)$. At 4-year follow-up, the rates of TVF ( $15.2 \%$ vs $14.6 \% ; P=0.68)$, cardiac death $(5.4 \%$ vs $4.7 \%$; $P=0.44)$, target vessel MI (5.3\% vs $5.4 \% ; P=1.00)$, clinically indicated TLR ( $7.0 \%$ vs $6.5 \% ; P=0.62$ ), and definite/probable ST $(2.3 \%$ vs $1.6 \% ; P=0.23)$ were similar with the Resolute ZES (R-ZES) and EES.

In a recent propensity-matched study of 400 diabetic patients, Miyazaki et al ${ }^{48}$ showed no significant differences in MACE (death, MI, and TVR) in all-comer diabetics treated with R-ZES ( $\mathrm{n}=128)$ or EES ( $\mathrm{n}=128)$ (ZES: $20.9 \%$ vs EES: $25.3 \% ; P=0.47)$. In a recent meta-analysis by Piccolo et a ${ }^{49}$ comparing the R-ZES and EES (five trials that included a total of 9,899 patients), similar risks in TVR, definite ST, cardiac death, and target vessel MI were shown. Compared with EES, R-ZES had similar risks of TVR (HR $=1.06 ; 95 \%$ confidence interval [CI]: 0.90 to $1.24 ; P=0.50$ ), definite or probable ST (HR $=1.26 ; 95 \%$ CI: 0.86 to $1.85 ; P=0.24$ ), cardiac death (HR $=1.01 ; 95 \% \mathrm{CI}: 0.79$ to $1.30 ; P=0.91$ ), and target-vessel MI (relative risk [RR]: $1.10 ; 95 \% \mathrm{CI}: 0.89$ to $1.36 ; P=0.39$ ).

\section{EES versus SESs}

Although randomized trials between EES and PES have shown overall favorable results for EES, fewer clinically apparent differences were evident when EES and SES were compared. The All-comers Scandinavian Organization for Randomized Trials with Clinical Outcome IV (SORT OUT IV) trial ${ }^{50}$ enrolled 2,774 patients randomly assigned to either EES (Xience V, n=1,390) or SES (Cypher Select Plus, $n=1,384$ ) and followed through the Danish Civil Registration System. At 9 months of follow-up, no significant differences were observed between the two groups in terms of MACE (EES: $4.9 \%$ vs SES: $5.2 \%$; $P_{\text {noninferiority }}=0.01$ ), although definite ST occurred in fewer patients with EES compared with SES at both 9 months $(0.1 \%$ vs $0.7 \% ; P=0.05)$ and 18 months $(0.2 \%$ vs $0.9 \% ; P=0.03)$. Three Korean randomized controlled studies demonstrated a trend toward reduced LLL among patients treated with SES vs those treated with EES, ${ }^{51,52}$ whereas EES appeared to link to more favorable clinical outcomes among diabetics..$^{53}$

The multicenter Efficacy of Xience/Promus Versus Cypher to Reduce Late Loss After Stenting (EXCELLENT) trial $^{52}$ aimed to demonstrate the noninferiority of EES compared with SES in preventing LLL at 9 months. Patients with left main coronary artery disease, recent ( $<72$ hours) MI, STEMI, cardiogenic shock, or LVEF $<25 \%$ were excluded. A total of 1,443 patients undergoing PCI were randomized in a 3:1 ratio to receive EES (Xience V) or SES (Cypher Select). In-segment LLL at 9 months was $0.11 \pm 0.38 \mathrm{~mm}$ and $0.06 \pm 0.36 \mathrm{~mm}$ for EES and SES, respectively ( $P_{\text {non- }}$ inferiority $=0.038$, using a noninferiority margin of $0.1 \mathrm{~mm}$ ). Another randomized study from Korea, The Percutaneous Treatment of LONG Native Coronary Lesions With DrugEluting Stent-III (LONG-DES-III) trial, ${ }^{51}$ compared the use of long EES (Xience V/Promus) with SES (Cypher Select) in 450 patients with long ( $\geq 25 \mathrm{~mm}$ ) native coronary lesions. The primary end point of the trial was in-segment LLL at 9-month angiographic follow-up. In-segment LLL between the EES group and the SES group was $0.08 \mathrm{~mm}(95 \% \mathrm{CI}$ : 0.02 to 0.14 ), a result failing to show the noninferiority of the EES $\left(P_{\text {noninferiority }}=0.96\right.$ using a margin of $0.1 \mathrm{~mm}$ ) and instead demonstrating the statistical superiority of the SES $\left(P_{\text {superiority }}=0.042\right)$.

The Everolimus-Eluting Stent Versus Sirolimus-Eluting Stent Implantation for De Novo Coronary Artery Disease in Patients with Diabetes Mellitus (ESSENCE-DIABETES) randomized study compared EES $(n=149)$ and SES $(n=151)$ implantation in diabetic patients. The primary end point was noninferiority of angiographic in-segment LLL at 8 months. EESs were noninferior to SESs in terms of 8-month insegment LLL $(0.23 \pm 0.27 \mathrm{~mm}$ vs $0.37 \pm 0.52 \mathrm{~mm}$; difference: $-0.13 \mathrm{~mm}$; $95 \% \mathrm{CI}:-0.25$ to -0.02 ; upper one-sided $95 \%$ CI: $-0.04 ; P_{\text {noninferiority }}<0.001 ; P_{\text {superiority }}=0.02$ ). 
In the recent BIOFLOW-II randomized controlled trial, ${ }^{54}$ 452 patients were randomly assigned in a $2: 1$ ratio to treatment with the novel ultrathin strut, biodegradable polymer Orsiro (Biotronik, Bülach, Switzerland) O-SES (298 patients, 332 lesions) or Xience Prime X-EES (154 patients, 173 lesions) in a multicenter, noninferiority trial. The biodegradable polymer SES (Orsiro) is a novel DES consisting of an ultrathin $(60 \mu \mathrm{m})$ CoCr L605 platform covered with an amorphous silicon carbide layer and releases sirolimus from a biodegradable PLLA polymer. In terms of the primary end point, in-stent LLL at 9 months, O-SES was noninferior to X-EES $(0.10 \pm 0.32 \mathrm{~mm}$ vs $0.11 \pm 0.29 \mathrm{~mm}$; difference $=0.00063 \mathrm{~mm} ; 95 \% \mathrm{CI}:-0.06$ to $0.07 ; P$ $<0.0001)$. Both groups showed similar rates of TLF at 1 year (O-SES: $6.5 \%$ vs X-EES: $8.0 \%$; HR $=0.82 ; 95 \%$ CI: 0.40 to $\left.1.68 ; P_{\text {log-rank }}=0.58\right)$ without cases of ST. In the much larger BIOSCIENCE trial, ${ }^{55}$ 1,056 patients were randomized to CoCr EES and 2,119 to O-SES. At 12-month follow-up, there were no significant differences in the rates of TLF (cardiac death, MI, clinically indicated TLR): O-SES: 6.7\% vs EES: $6.7 \%(P=0.950)$.

In the multicenter Xience V stent vs Cypher stent in Primary PCI for Acute Myocardial Infarction (XAMI) trial, ${ }^{56}$ 625 patients were randomized (2:1 ratio) to EES or SES. At 3 -year follow-up, the primary end point (cardiac death, nonfatal MI, TVR) was $8.0 \%$ for EES and $10.5 \%$ for SES $(P=0.30)$. Cardiac death was low and comparable in both groups (EES: $2.5 \%$ vs SES: $2.7 \% ; P=0.86)$, as was definite/probable ST (EES: $2.3 \%$ vs SES $3.2 \%$; $P=0.60$ ). In the Randomized Comparison of Everolimus-Eluting Stents and Sirolimus-Eluting Stents in Patients With ST Elevation Myocardial Infarction (RACES-MI) trial, ${ }^{57} 500$ STEMI patients were randomized to EES or SES. No significant difference was observed between EES and SES in MACEs (16\% vs 20.8\%; $P=0.17)$, cardiac death (4.4\% vs 5.6\%; $P=0.53)$, recurrent MI (6.4\% vs $10 \%$; $P=0.13$ ), and TVR ( $4.8 \%$ vs $4.8 \% ; P=0.99)$. However, EES was associated with a significant reduction in ST $(1.6 \%$ vs $5.2 \% ; P=0.035)$.

A recent meta-analysis ${ }^{58}$ of 14 randomized trials ( $n=13,434$ patients) comparing EES vs SES using the longest available follow-up data revealed that EES was associated with significantly lower risk for definite ST (odds ratio [OR]: 0.66; $95 \%$ CI: 0.38 to 0.9 ), TLR (OR: 0.83 ; 95\% CI: 0.7 to 0.98), and MACE (OR: 0.86 ; $95 \%$ CI: 0.76 to 0.96 ). The direction and magnitude of the effect beyond 1 year were comparable with those observed within 1 year.

Another meta-analysis of 13 randomized studies ${ }^{59}$ ( $n=17,101$ patients, weighted mean follow-up: 21.7 months) revealed that EES significantly reduced ST (RR: 0.55; 95\% CI: 0.38 to $0.78 ; P=0.001$ ) compared to non-EES stents, an association that was independent of follow-up time or DAT duration, but that was mainly driven by randomized studies comparing EES with PES.

\section{PtCr EES trials}

The randomized Prospective, Randomized, Multicenter Trial to Assess an Everolimus Eluting Coronary Stent System PROMUS Element for the Treatment of Up to Two de Novo Coronary Artery Lesions (PLATINUM) trial ${ }^{10}$ randomly assigned 1,530 patients undergoing PCI of one or two de novo native lesions to treatment with either the standard CoCr EES Xience V $(n=762)$ or the new PtCr PROMUS Element $(n=768)$ stent. The primary end point was the 12-month rate of TLF, the composite of target vessel cardiac death, target vessel MI, or ID-TLR. This occurred in $2.9 \%$ vs $3.4 \%$ of patients assigned to CoCr EES versus PtCr EES, respectively (difference: $0.5 \%$; $95 \% \mathrm{CI}:-1.3 \%$ to $\left.2.3 \% ; P_{\text {noninferiority }}<0.001 ; P_{\text {superiority }}=0.60\right)$, suggesting similar outcomes. The Harmonizing Optimal Strategy for Treatment of Coronary Artery Stenosis-Safety and Effectiveness of Drug-Eluting Stents and Antiplatelet Regimen (HOST ASSURE) trial ${ }^{60}$ aimed to compare a PtCr EES (PROMUS element, Boston Scientific) to the CoCr-based ZES (Resolute; Medtronic, Minneapolis, MN, USA). At 1 year, TLF occurred in $2.9 \%$ and $2.9 \%$ of the PtCr-EES and CoCr-ZES groups, respectively $\left(P_{\text {superiority }}=0.98 ; P_{\text {noninferiority }}=0.02\right)$. There were no significant differences in the individual components of TLF as well as in the patient-oriented clinical outcomes.

The recent EVOLVE II randomized trial ${ }^{61}$ assessed the safety and efficacy of a novel PtCr bioresorbable polymercoated EES (SYNERGY stent, Boston Scientific) versus the PtCr PROMUS Element Plus. The primary end point of 12 -month TLF was observed in $6.7 \%$ of SYNERGY- and 6.5\% PROMUS Element Plus-treated subjects by intention to treat $\left(P_{\text {noninferiority }}=0.0005\right)$.

The PLATINUM China randomized clinical trial ${ }^{62}$ evaluated the safety and effectiveness of the PtCr PROMUS Element EES (Boston Scientific, Marlborough, MA, USA) and compared the 9-month LLL to PES (Taxus Liberté) (PtCr EES, $n=373$ vs PES, $n=127,3: 1$ randomization). Nine-month in-stent LLL was significantly lower in the PtCr EES group (PES: 0.40 $\pm 0.45 \mathrm{~mm}$ vs PtCr EES: $0.11 \pm 0.36 \mathrm{~mm} ; P<0.001$ ). The 1-year rate of death/MI was $1.6 \%(2 / 127)$ for PES versus $0 \%(0 / 371)$ for PtCr EES $(P=0.06)$ and TVR was $4.7 \%$ (6/127) for PES versus 2.7\% (10/371) for PtCr EES ( $P=0.26)$. No ST occurred at 12 months in either group. 


\section{Everolimus-eluting BRSs}

Despite improvements in the safety profile of DESs, ${ }^{63}$ LLL, late ST, and permanent vessel caging remain inherited limitations. BRSs provide temporary support to the vessel wall and subsequently disappear in approximately 3 years. The only everolimus BRS currently approved for clinical use in Europe is the Absorb v1.1 (bioresorbable vascular scaffold [BVS]; Abbott Vascular) made of PLLA, which degrades gradually over time via hydrolysis.

The initial experience with BVS implantation in de novo simple lesions has been promising, with acceptable long-term outcomes (MACE: $3.4 \%$ ) in the ABSORB Cohort A, ${ }^{64}$ a study of 30 patients with single de novo lesions who were treated with Absorb v1.0. At 5 years follow-up, there was an increase in minimal luminal diameter and area, which was primarily attributed due to a persistent reduction in plaque area size. The ABSORB ${ }^{65}$ multi-imaging modality study (45 patients [Cohort B1] and 56 patients [Cohort B2]) revealed unchanged LLL after the first year of Absorb 1.1 implantation, whereas on intravascular ultrasound, the mean lumen, scaffold, and vessel areas showed enlargement up to 2 years. In the ABSORB II randomized controlled trial, ${ }^{66} 335$ patients treated with Absorb v1.1 were compared to 166 patients treated with a permanent metallic EES (Xience, Abbott Vascular). The ABSORB II included patients with one, or maximum two, de novo relatively simple lesions (ostial, left main coronary artery, bifurcation, chronic total occlusion, heavily calcified, or ISR lesions were all excluded). Despite the lower postimplantation acute lumen gain observed in lesions treated with BVS, 1-year TLF (composite of cardiac death, target-vessel MI, or clinically indicated TLR) was similar between the two groups (BVS vs EES: $5 \%$ vs $3 \% ; P=0.35$ ). The Comparison of Everolimus- and Biolimus-Eluting Stents With Everolimus-Eluting Bioresorbable Vascular Scaffold Stents II (EVERBIO II) trial, ${ }^{67}$ a single-center, assessor-blinded study of 240 patients randomly assigned in a 1:1:1 ratio to BVS, PROMUS Element PtCr EES, and biolimus-eluting stent (Biomatrix FLEX, Biosensors, Newport Beach, CA, USA), showed no difference in angiographic LLL 9 months after stent/scaffold implantation in all-comer patients (BVS: $0.28 \pm 0.39 \mathrm{~mm}$; EES/BES: $0.25 \pm 0.36 \mathrm{~mm} ; P=0.30$ ). In realworld patients, a small propensity-matched study by Costopoulos et al ${ }^{68}$ demonstrated similar 1-year MACE (3.3\% vs $7.6 \% ; P=0.19)$ in patients treated with Absorb v1.1 versus newer-generation EES, respectively. The large "real-world" multicenter GHOST-EU registry, ${ }^{69}$ consisting of 1,189 patients, showed a TLF rate of $3.5 \%$ at the median followup time of 109 days. Despite the acceptable TLF of $4.4 \%$ at 6 months, estimated by the Kaplan-Meier method, the GHOST-EU registry revealed some worrying signals of BVS thrombosis ( $1.5 \%$ at 30 days; $2.1 \%$ at 6 months). In the Dutch Academic Medical Center (AMC) real-world registry, ${ }^{70} 135$ patients (159 lesions) treated with Absorb v1.1 and followed up for 6 months demonstrated TVR rates of $8.5 \%$, including a $6.3 \%$ TLR rate, a $3 \%$ rate of MI, and a $3 \%$ rate of definite BVS thrombosis (three subacute and one late), concurring with the GHOST-EU findings. In the BVS Expand ${ }^{71}$ single-center registry of 200 patients, which excluded patients with STEMI and previous coronary artery bypass grafting $(\mathrm{CABG})$, the 6-month rate of MACE was 3.3\%, TLR 2.2\%, and MI 1.7\%, whereas $2.2 \%(n=4)$ definite BVS thrombosis cases occurred. The findings from these three studies (GHOST-EU, AMC, and BVS Expand) suggest that the current BVS generation, which is characterized by significantly thicker and wider struts $(\sim 150 \times 200 \mu \mathrm{m})$ compared to new-generation DESs $(80 \times 80 \mu \mathrm{m})$ may be more thrombogenic, particularly when underexpanded or malapposed. In the German multicenter ASSURE (ABSORB: Postmarketing Surveillance Registry to Monitor the Everolimus-eluting Bioresorbable Vascular Scaffold in Patients With Coronary Artery Disease) registry, ${ }^{72} 183$ patients treated with Absorb v1.1 were followed up for 1 year. Of note, this study excluded long lesions (defined as $>28 \mathrm{~mm}$ ) and lesions with a vessel diameter of $>3.3 \mathrm{~mm}$. The 1-year rate for MACE was $5 \%$, TLR $2.8 \%$, and MI 1.6\%, whereas no scaffold thrombosis was observed. The ABSORB first registry, ${ }^{73}$ a multicenter (1,200 patients), prospective global registry of "real world" patients treated with Absorb v1.1, demonstrated a 30-day MI rate of 0.8\%, whereas no cardiac deaths were reported. Definite or probable scaffold thrombosis rates were $0.42 \%$, almost a third of those reported in the GHOST EU. The Bioresorbable Vascular Scaffold-A Clinical Evaluation of Everolimus Eluting Coronary Stents in the Treatment of Patients With ST-segment Elevation Myocardial Infarction (BVS-EXAMINATION) trial $^{74}$ studied propensity-matched STEMI patients treated with BVS, CoCr EES Xience V, or BMS (290 patients in each group). The cumulative incidence of device-oriented clinical end points did not differ between the BVS and EES/BMS groups at 1 year ( $4.1 \%$ vs $4.1 \%, P=0.994$; vs $5.9 \%, P=0.306$, respectively). Definite/probable thrombosis rate in the BVS group was numerically higher at both 30 days $(2.1 \%$ vs $0.3 \%[P=0.059]$ vs $1.0 \%[P=0.324]$, respectively) and 1 year ( $2.4 \%$ vs $1.4 \%[P=0.948]$ vs $1.7 \%[P=0.825]$, respectively), as compared with the EES or BMS groups. Several smaller registries have demonstrated the feasibility of implantation of BVS in more complex lesions,${ }^{75}$ such as calcified lesions ${ }^{76}$ or 


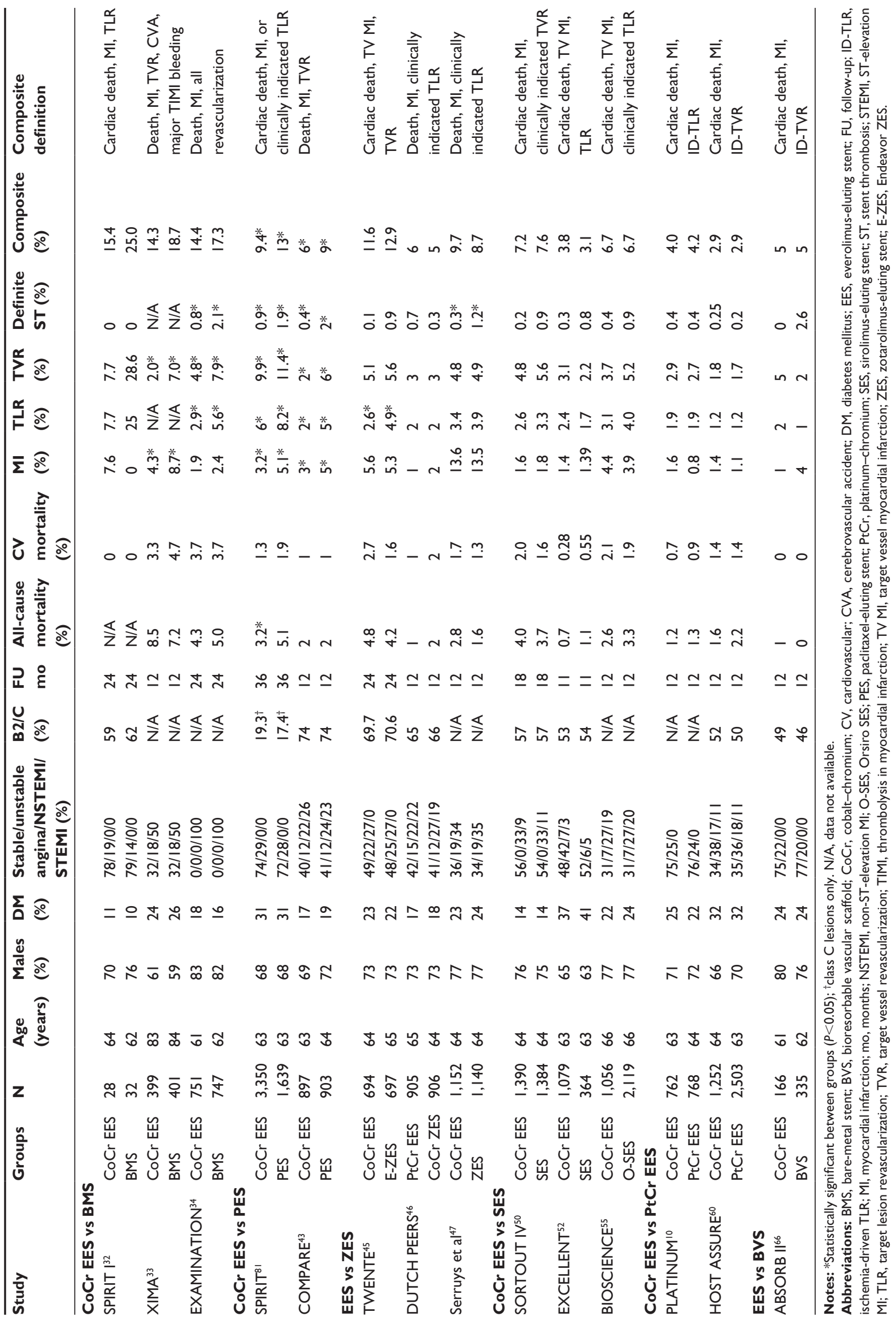


ISR. ${ }^{77}$ Table 2 shows the landmark studies in patients treated with EESs/everolimus-eluting scaffolds.

The main current drawback of everolimus BRS (Absorb v1.1) relates to its strut thickness and width $(157 \times 190.5 \mu \mathrm{m}$ for the $2.5 \mathrm{~mm}$ and $3.0 \mathrm{~mm}$ scaffolds and $157 \times 215.9 \mu \mathrm{m}$ for the $3.5 \mathrm{~mm}$ scaffold), which may render it more thrombogenic, particularly when underexpanded or malapposed. Ishibashi et $\mathrm{al}^{78}$ summarized the BRS thrombosis experience in various settings (stable angina, ACS, and STEMI). In the total population of 4,309 patients implanted with BRS (Absorb v1.1) and followed up for 10.3 months, definite/ probable BRS thrombosis was seen in $1.22 \%$ of patients, of which $0.16 \%$ of cases were acute and $0.76 \%$ subacute. BRS thrombosis occurred in $0.94 \%$ of patients presenting with stable angina, $2.16 \%$ in those with ACS, and $1.22 \%$ in patients with STEMI. Large randomized controlled trials purposefully powered are needed to demonstrate whether there is truly an excess risk of device thrombosis in patients treated with BRS compared to new-generation ultrathin EES. This potentially increased risk in BRS-treated patients highlights 1) the importance of optimal scaffold implantation technique using intracoronary imaging and 2) the need for novel scaffolds with thinner struts $(<100 \mu \mathrm{m})$.

\section{EESs versus coronary artery bypass for multivessel disease}

Two recent studies have attempted to address the question whether percutaneous or surgical revascularization is most appropriate for patients with multivessel disease, not involving the left main coronary artery. In the first study, Park et $\mathrm{al}^{79}$ conducted a noninferiority randomized trial in 27 centers in East Asia comparing treatment of multivessel coronary disease with either EES PCI or CABG. The study, which was initially forecasted to recruit 1,776 patients, was prematurely terminated due to slow enrollment pace. The overall number of patients enrolled was 880 patients and was balanced between the two groups $\left(n_{\mathrm{PCI}}=438\right.$ and $\left.n_{\mathrm{CABG}}=442\right)$ and the primary end point was the composite of death, MI, or TVR. The mean Euroscore was around 3.0 for both groups, whereas the mean SYNTAX score was $\sim 24$. Only $15.1 \%$ of patients in the PCI group and $17.9 \%$ of patients in the CABG group had a SYNTAX score $\geq 33$. At 2 years of follow-up, the primary end point occurred in $11.0 \%$ of the patients in the PCI group and in $7.9 \%$ of those in the CABG group (absolute risk difference: $3.1 \% ; 95 \% \mathrm{CI}:-0.8$ to $6.9 ; P_{\text {noninferiority }}=0.32$ ), whereas at a longer-term follow-up (median: 4.6 years), the primary end point occurred in $15.3 \%$ of the patients in the PCI group and in $10.6 \%$ of those in the CABG group ( $\mathrm{HR}=1.47$; $95 \% \mathrm{CI}$ :
1.01 to $2.13 ; P=0.04)$. Nevertheless, these results have to be cautiously interpreted, as the study was underpowered for the primary end point. Of note, $\sim 30 \%$ of patients in both groups had chronic total occlusions, whereas complete revascularization occurred more frequently in the CABG group than in the PCI group ( $71.5 \%$ vs $50.9 \% ; P<0.001)$. No fractional flow reserve or other pressure-wire measurements were utilized to guide revascularization in either group. Among patients with diabetes, the rate of the primary end point was significantly higher among those assigned to PCI than among those assigned to $\mathrm{CABG}(19.2 \%$ vs $9.1 \% ; P=0.007)$.

The second propensity-matched study by Bangalore et al, ${ }^{80}$ compared PCI vs CABG in 34,819 patients with multivessel disease (excluding left main coronary artery disease). In contrast to the previous study, all-cause mortality was defined as the primary end point for this trial (9,223 PCI vs 9,223 CABG patients). At a mean follow-up of 2.9 years, PCI with EES, as compared with $\mathrm{CABG}$, had similar mortality rates $(\mathrm{HR}=1.04$; 95\% CI: 0.93 to $1.17 ; P=0.50)$. Nevertheless, in the same time frame, PCI conferred higher risk for $\mathrm{MI}(\mathrm{HR}=1.51$; 95\% CI: 1.29 to $1.77 ; P<0.001)$ and repeat revascularization ( $\mathrm{HR}=2.35 ; 95 \% \mathrm{CI}: 2.14$ to $2.58 ; P<0.001)$, but a lower risk for stroke ( $\mathrm{HR}=0.62 ; 95 \% \mathrm{CI}$ : 0.50 to $0.76 ; P<0.001)$.

\section{Conclusion}

In the current review, we have summarized the inception and the rapid evolution of EES platforms. Several randomized controlled trials and meta-analyses have demonstrated the superior efficacy and safety of EESs, initially over BMSs and subsequently over DESs, namely, PESs and SESs. Among diabetics, these improved outcomes have not been confirmed, and future research is required to determine the differential response of this subgroup of patients to different antiproliferative drugs. Similar safety and efficacy profiles have been demonstrated between EES and the new ZES platforms. The developments of the bioresorbable polymercoated EES SYNERGY and the everolimus-eluting BRS (Absorb v1.1) are considered revolutionary, and results from further randomized studies with larger patient numbers and broader inclusion criteria are eagerly awaited to demonstrate whether these new technologies can match or improve upon the already excellent outcomes from the $\mathrm{CoCr}$ and the novel ultrathin $\mathrm{PtCr}$ platforms in all-comer patients.

\section{Future perspectives}

Several manufacturers of everolimus-eluting BRSs are working on reducing strut thickness $(<100 \mu \mathrm{m})$, increasing radial strength, increasing size range, reducing absorption 
time to $\sim 1$ year, and improving BRS deliverability. These improved technical characteristics will enable BRS to tackle the majority of complex lesions while simultaneously minimizing procedure times and optimizing future outcomes. In the next decade, these novel scaffolds will need to go through a series of head-to-head comparisons with state-of-the-art PtCr EESs (with either durable or bioresorbable polymer) to demonstrate their superior long-term efficacy and safety, aiming to eradicate very late ST.

\section{Disclosure}

The authors report no conflicts of interest in this work.

\section{References}

1. Grüntzig AR, Senning $\AA$, Siegenthaler WE. Nonoperative dilatation of coronary-artery stenosis. N Engl J Med. 1979;301(2):61-68.

2. Nabel EG, Braunwald E. A tale of coronary artery disease and myocardial infarction. N Engl J Med. 2012;366(1):54-63.

3. Fischman DL, Leon MB, Baim DS, et al. A randomized comparison of coronary-stent placement and balloon angioplasty in the treatment of coronary artery disease. Stent Restenosis Study Investigators. $N$ Engl J Med. 1994;331(8):496-501.

4. Serruys PW, de Jaegere P, Kiemeneij F, et al. A comparison of balloonexpandable-stent implantation with balloon angioplasty in patients with coronary artery disease. Benestent Study Group. $N$ Engl J Med. 1994;331(8):489-495.

5. Morice MC, Serruys PW, Sousa JE, et al. A randomized comparison of a sirolimus-eluting stent with a standard stent for coronary revascularization. $N$ Engl J Med. 2002;346(23):1773-1780.

6. Joner M, Finn AV, Farb A, et al. Pathology of drug-eluting stents in humans: delayed healing and late thrombotic risk. $J$ Am Coll Cardiol. 2006;48(1):193-202.

7. Menown IB, Noad R, Garcia EJ, Meredith I. The platinum chromium element stent platform: from alloy, to design, to clinical practice. $A d v$ Ther. 2010;27(3):129-141.

8. Iqbal J, Onuma Y, Ormiston J, Abizaid A, Waksman R, Serruys P. Bioresorbable scaffolds: rationale, current status, challenges, and future. Eur Heart J. 2014;35(12):765-776.

9. O'Brien BJ, Stinson JS, Larsen SR, Eppihimer MJ, Carroll WM. A platinum-chromium steel for cardiovascular stents. Biomaterials. 2010;31(14):3755-3761.

10. Stone GW, Teirstein PS, Meredith IT, et al. A prospective, randomized evaluation of a novel everolimus-eluting coronary stent: the PLATINUM (A prospective, randomized, multicenter trial to assess an everolimus-eluting coronary stent system [promus element] for the treatment of up to Two De Novo Coronary Artery Lesions) Trial. J Am Coll Cardiol. 2011;57(16):1700-1708.

11. Thomas MR, Birkemeyer R, Schwimmbeck P, et al. One-year outcomes in 1,010 unselected patients treated with the PROMUS Element everolimuseluting stent: the multicentre PROMUS Element European Post-Approval Surveillance Study. EuroIntervention. 2015;10(11): 1267-1271.

12. Ormiston JA, Webber B, Ubod B, White J, Webster MW. Coronary stent durability and fracture: an independent bench comparison of six contemporary designs using a repetitive bend test. EuroIntervention. 2015;10(12):1449-1455.

13. Gogas BD, Farooq V, Onuma Y, Serruys PW. The ABSORB bioresorbable vascular scaffold: an evolution or revolution in interventional cardiology? Hellenic J Cardiol. 2012;53(4):301-309.

14. Welt FG, Rogers C. Inflammation and restenosis in the stent era. Arterioscler Thromb Vasc Biol. 2002;22(11):1769-1776.
15. Costa MA, Simon DI. Molecular basis of restenosis and drug-eluting stents. Circulation. 2005;111(17):2257-2273.

16. Carter AJ. TOR of the cell cycle: are there important implications for diabetics in the era of the drug-eluting stent? Catheter Cardiovasc Interv. 2004;61(2):233-236.

17. Schuler W, Sedrani R, Cottens S, et al. SDZ RAD, a new rapamycin derivative: pharmacological properties in vitro and in vivo. Transplantation. 1997;64(1):36-42.

18. Eisen HJ, Tuzcu EM, Dorent R, et al. Everolimus for the prevention of allograft rejection and vasculopathy in cardiac-transplant recipients. N Engl J Med. 2003;349(9):847-858.

19. Verheye S, Martinet W, Kockx MM, et al. Selective clearance of macrophages in atherosclerotic plaques by autophagy. $J$ Am Coll Cardiol. 2007;49(6):706-715.

20. Kahan BD, Wong RL, Carter C, et al. A phase I study of a 4-week course of SDZ-RAD (RAD) quiescent cyclosporine-prednisone-treated renal transplant recipients. Transplantation. 1999;68(8):1100-1106.

21. Rogers CD. Optimal stent design for drug delivery. Rev Cardiovasc Med. 2004;5(Supp1 2):S9-S15.

22. Kotani J, Awata M, Nanto S, et al. Incomplete neointimal coverage of sirolimus-eluting stents: angioscopic findings. $\mathrm{J} \mathrm{Am} \mathrm{Coll} \mathrm{Cardiol.}$ 2006;47(10):2108-2111.

23. Finn AV, Joner M, Nakazawa G, et al. Pathological correlates of late drug-eluting stent thrombosis: strut coverage as a marker of endothelialization. Circulation. 2007;115(18):2435-2441.

24. Daemen J, Wenaweser P, Tsuchida K, et al. Early and late coronary stent thrombosis of sirolimus-eluting and paclitaxel-eluting stents in routine clinical practice: data from a large two-institutional cohort study. Lancet. 2007;369(9562):667-678.

25. Carter AJ, Brodeur A, Collingwood R, et al. Experimental efficacy of an everolimus eluting cobalt chromium stent. Catheter Cardiovasc Interv. 2006;68(1):97-103.

26. Windecker S, Kolh P, Alfonso F, et al. 2014 ESC/EACTS Guidelines on myocardial revascularization: the Task Force on Myocardial Revascularization of the European Society of Cardiology (ESC) and the European Association for Cardio-Thoracic Surgery (EACTS) Developed with the special contribution of the European Association of Percutaneous Cardiovascular Interventions (EAPCI). Eur Heart J. 2014;35(37):2541-2619.

27. Grube E, Sonoda S, Ikeno F, et al. Six- and twelve-month results from first human experience using everolimus-eluting stents with bioabsorbable polymer. Circulation. 2004;109(18):2168-2171.

28. Costa RA, Lansky AJ, Mintz GS, et al. Angiographic results of the first human experience with everolimus-eluting stents for the treatment of coronary lesions (the FUTURE I trial). Am J Cardiol. 2005;95(1):113-116.

29. Tsuchiya Y, Lansky AJ, Costa RA, et al. Effect of everolimus-eluting stents in different vessel sizes (from the pooled FUTURE I and II trials). Am J Cardiol. 2006;98(4):464-469.

30. Serruys PW, Ong AT, Piek JJ, et al. A randomized comparison of a durable polymer everolimus-eluting stent with a bare metal coronary stent: the SPIRIT first trial. EuroIntervention. 2005;1(1):58-65.

31. Tsuchida K, Piek JJ, Neumann FJ, et al. One-year results of a durable polymer everolimus-eluting stent in de novo coronary narrowings (The SPIRIT FIRST Trial). EuroIntervention. 2005;1(3):266-272.

32. Beijk MA, Neumann FJ, Wiemer M, et al. Two-year results of a durable polymer everolimus-eluting stent in de novo coronary artery stenosis (The SPIRIT FIRST Trial). EuroIntervention. 2007;3(2):206-212.

33. de Belder A, de la Torre Hernandez JM, Lopez-Palop R, et al. A prospective randomized trial of everolimus-eluting stents versus bare-metal stents in octogenarians: the XIMA Trial (Xience or vision stents for the management of angina in the elderly). J Am Coll Cardiol. 2014;63(14):1371-1375.

34. Sabate M, Brugaletta S, Cequier A, et al. The EXAMINATION trial (everolimus-eluting stents versus bare-metal stents in ST-segment elevation myocardial infarction): 2-year results from a multicenter randomized controlled trial. JACC Cardiovasc Interv. 2014;7(1):64-71.

35. Kaiser C, Galatius S, Erne P, et al. Drug-eluting versus bare-metal stents in large coronary arteries. $N$ Engl J Med. 2010;363(24):2310-2319. 
36. Valgimigli M, Sabate M, Kaiser C, et al. Effects of cobalt-chromium everolimus eluting stents or bare metal stent on fatal and non-fatal cardiovascular events: patient level meta-analysis. BMJ. 2014;349:g6427.

37. Serruys PW, Ruygrok P, Neuzner J, et al. A randomised comparison of an everolimus-eluting coronary stent with a paclitaxel-eluting coronary stent: the SPIRIT II trial. EuroIntervention. 2006;2(3):286-294.

38. Onuma Y, Miquel-Hebert K, Serruys PW. Five-year long-term clinical follow-up of the XIENCE V everolimus-eluting coronary stent system in the treatment of patients with de novo coronary artery disease: the SPIRIT II trial. EuroIntervention. 2013;8(9):1047-1051.

39. Stone GW, Midei M, Newman W, et al. Comparison of an everolimuseluting stent and a paclitaxel-eluting stent in patients with coronary artery disease: a randomized trial. JAMA. 2008;299(16):1903-1913.

40. Gada H, Kirtane AJ, Newman W, et al. 5-year results of a randomized comparison of XIENCE V everolimus-eluting and TAXUS paclitaxeleluting stents: final results from the SPIRIT III trial (clinical evaluation of the XIENCE V everolimus eluting coronary stent system in the treatment of patients with de novo native coronary artery lesions). JACC Cardiovasc Interv. 2013;6(12):1263-1266.

41. Stone GW, Rizvi A, Newman W, et al. Everolimus-eluting versus paclitaxel-eluting stents in coronary artery disease. $N$ Engl $J$ Med. 2010;362(18): 1663-1674.

42. Stone G. A large scale randomized comparison of everolimus-eluting and paclitaxel-eluting stents: three-year outcomes from the SPIRIT IV trial. Presented at Transcatheter Cardiovascular Therapeutics; San Francisco, CA, USA. November 7-11, 2011.

43. Smits PC, Kedhi E, Royaards KJ, et al. 2-year follow-up of a randomized controlled trial of everolimus- and paclitaxel-eluting stents for coronary revascularization in daily practice. COMPARE (Comparison of the everolimus eluting XIENCE-V stent with the paclitaxel eluting TAXUS LIBERTE stent in all-comers: a randomized open label trial). J Am Coll Cardiol. 2011;58(1):11-18.

44. Kedhi E, Joesoef KS, McFadden E, et al. Second-generation everolimuseluting and paclitaxel-eluting stents in real-life practice (COMPARE): a randomised trial. Lancet. 2010;375(9710):201-209.

45. Tandjung K, Sen H, Lam MK, et al. Clinical outcome following stringent discontinuation of dual antiplatelet therapy after 12 months in real-world patients treated with second-generation zotarolimus-eluting resolute and everolimus-eluting Xience V stents: 2-year follow-up of the randomized TWENTE trial. J Am Coll Cardiol. 2013;61(24):2406-2416.

46. von Birgelen C, Sen H, Lam MK, et al. Third-generation zotarolimus-eluting and everolimus-eluting stents in all-comer patients requiring a percutaneous coronary intervention(DUTCH PEERS): a randomised, single-blind, multicentre, non-inferiority trial. Lancet. 2014;383(9915):413-423.

47. Serruys PW, Silber S, Garg S, et al. Comparison of zotarolimus-eluting and everolimus-eluting coronary stents. $N$ Engl J Med. 2010;363(2):136-146.

48. Miyazaki T, Latib A, Panoulas VF, et al. Comparison of 2-year outcomes between zotarolimus-eluting and everolimus-eluting new-generation cobalt-chromium alloy stents in real-world diabetic patients. Catheter Cardiovasc Interv. 2015;86(1):E11-E18.

49. Piccolo R, Stefanini GG, Franzone A, et al. Safety and efficacy of resolute zotarolimus-eluting stents compared with everolimus-eluting stents: a meta-analysis. Circ Cardiovasc Interv. 2015;8(4).

50. Jensen LO, Thayssen P, Hansen HS, et al. Randomized comparison of everolimus-eluting and sirolimus-eluting stents in patients treated with percutaneous coronary intervention: the Scandinavian organization for randomized trials with clinical outcome IV (SORT OUT IV). Circulation. 2012;125(10):1246-1255.

51. Park D-W, Kim Y-H, Song H-G, et al. Comparison of everolimus- and sirolimus-Eluting stents in patients with long coronary artery lesions: a randomized LONG-DES-III (percutaneous treatment of LONG native coronary lesions with drug-eluting stent-III) trial. JACC Cardiovasc Interv. 2011;4(10):1096-1103.

52. Park KW, Chae I-H, Lim D-S, et al. Everolimus-eluting versus sirolimuseluting stents in patients undergoing percutaneous coronary intervention: the EXCELLENT (efficacy of XIENCE/Promus versus Cypher to reduce late loss after stenting) randomized trial. J Am Coll Cardiol. 2011;58(18):1844-1854.
53. Kim W-J, Lee S-W, Park S-W, et al. Randomized comparison of everolimus-eluting stent versus sirolimus-eluting stent implantation for De Novo coronary artery disease in patients with diabetes mellitus (ESSENCE-DIABETES): results from the ESSENCE-DIABETES trial. Circulation. 2011;124(8):886-892.

54. Windecker S, Haude M, Neumann FJ, et al. Comparison of a novel biodegradable polymer sirolimus-eluting stent with a durable polymer everolimus-eluting stent: results of the randomized BIOFLOW-II trial. Circ Cardiovasc Interv. 2015;8(2):e001441.

55. Pilgrim T, Heg D, Roffi M, et al. Ultrathin strut biodegradable polymer sirolimus-eluting stent versus durable polymer everolimus-eluting stent for percutaneous coronary revascularisation (BIOSCIENCE): a randomised, single-blind, non-inferiority trial. Lancet. 2014;384(9960): 2111-2122.

56. Hofma SH, Smits PC, Brouwer J, et al. Long-term follow-up of secondgeneration everolimus-eluting stents versus first-generation sirolimuseluting stents in acute myocardial infarction: three-year results of the XAMI trial. EuroIntervention. 2015;10(11):1280-1283.

57. Di Lorenzo E, Sauro R, Varricchio A, et al. Randomized comparison of everolimus-eluting stents and sirolimus-eluting stents in patients with ST elevation myocardial infarction: RACES-MI trial. JACC Cardiovasc Interv. 2014;7(8):849-856.

58. Toyota T, Shiomi H, Morimoto T, Kimura T. Meta-analysis of longterm clinical outcomes of everolimus-eluting stents. Am J Cardiol. 2015;116(2):187-194.

59. Baber U, Mehran R, Sharma SK, et al. Impact of the everolimus-eluting stent on stent thrombosis: a meta-analysis of 13 randomized trials. J Am Coll Cardiol. 2011;58(15):1569-1577.

60. Park KW, Kang SH, Kang HJ, et al. A randomized comparison of platinum chromium-based everolimus-eluting stents versus cobalt chromiumbased zotarolimus-eluting stents in all-comers receiving percutaneous coronary intervention: HOST-ASSURE (harmonizing optimal strategy for treatment of coronary artery stenosis-safety and effectiveness of drug-eluting stents and anti-platelet regimen), a randomized, controlled, noninferiority trial. J Am Coll Cardiol. 2014;63(25 pt A): 2805-2816.

61. Kereiakes DJ, Meredith IT, Windecker S, et al. Efficacy and safety of a novel bioabsorbable polymer-coated, everolimus-eluting coronary stent: the EVOLVE II randomized trial. Circ Cardiovasc Interv. 2015;8(4).

62. Gao R, Han Y, Yang Y, et al. PLATINUM China: a prospective, randomized investigation of the platinum chromium everolimus-eluting stent in de novo coronary artery lesions. Catheter Cardiovasc Interv. 2015;85(Suppl 1):716-723.

63. Stefanini GG, Kalesan B, Serruys PW, et al. Long-term clinical outcomes of biodegradable polymer biolimus-eluting stents versus durable polymer sirolimus-eluting stents in patients with coronary artery disease (LEADERS): 4 year follow-up of a randomised non-inferiority trial. Lancet. 2011;378(9807):1940-1948.

64. Simsek C, Karanasos A, Magro M, et al. Long-term invasive followup of the everolimus-eluting bioresorbable vascular scaffold: five-year results of multiple invasive imaging modalities. EuroIntervention. 2014:20130724-03.

65. Bourantas CV, Farooq V, Zhang Y, et al. Circumferential distribution of the neointima at six-month and two-year follow-up after a bioresorbable vascular scaffold implantation: a substudy of the ABSORB Cohort B Clinical Trial. EuroIntervention. 2015;10(11):1299-1306.

66. Serruys PW, Chevalier B, Dudek D, et al. A bioresorbable everolimuseluting scaffold versus a metallic everolimus-eluting stent for ischaemic heart disease caused by de-novo native coronary artery lesions (ABSORB II): an interim 1-year analysis of clinical and procedural secondary outcomes from a randomised controlled trial. Lancet. 2015; 385(9962):43-54.

67. Puricel S, Arroyo D, Corpataux N, et al. Comparison of everolimus- and biolimus-eluting coronary stents with everolimus-eluting bioresorbable vascular scaffolds. J Am Coll Cardiol. 2015;65(8):791-801.

68. Costopoulos C, Latib A, Naganuma T, et al. Comparison of early clinical outcomes between ABSORB bioresorbable vascular scaffold and everolimus-eluting stent implantation in a real-world population. Catheter Cardiovasc Interv. 2015;85(1):E10-E15. 
69. Capodanno D, Gori T, Nef H, et al. Percutaneous coronary intervention with everolimus-eluting bioresorbable vascular scaffolds in routine clinical practice: early and midterm outcomes from the European multicentre GHOST-EU registry. EuroIntervention. 2015;10(10):1144-1153.

70. Kraak RP, Hassell ME, Grundeken MD, et al. Initial experience and clinical evaluation of the absorb bioresorbable vascular scaffold (BVS) in real-world practice: the AMC single centre real world PCI registry. EuroIntervention. 2015;10(10):1160-1168.

71. van Geuns RJ. BVS expand: 6-month results. Presented at: EuroPCR; 2014. Available from: http://www.pcronline.com/Lectures/2014/BVSExpand-6-month-results.

72. Woehrle J, Naber C, Schmitz T, et al. Beyond the ealy stages: insights from the ASSURE Registry on bioresorbable vascular scaffold. EuroIntervention. 2015;11(2):149-156.

73. Eeckhout E, Seth A, Mao VM, et al. ABSORB FIRST: an interim report on baseline characteristics and acute performance on the first 1,200 patients from a prospective, multi-center, global registry. $J \mathrm{Am}$ Coll Cardiol. 2014;64(11_S):679.

74. Brugaletta S, Gori T, Low AF, et al. Absorb bioresorbable vascular scaffold versus everolimus-eluting metallic stent in ST-segment elevation myocardial infarction: 1-year results of a propensity score matching comparison: the BVS-EXAMINATION Study (bioresorbable vascular scaffold-a clinical evaluation of everolimus eluting coronary stents in the treatment of patients with ST-segment elevation myocardial infarction). JACC Cardiovasc Interv. 2015;8(1 pt B):189-197.
75. Panoulas VF, Miyazaki T, Kawamoto H, Colombo A, Chieffo A. Bioresorbable scaffolds for the treatment of complex lesions: are we there yet? Interv Cardiol. 2015;7(1):35-54.

76. Panoulas VF, Miyazaki T, Sato K, et al. Procedural outcomes of patients with calcified lesions treated with bioresorbable vascular scaffolds. EuroIntervention. 2015;10(11):20141121-01.

77. Ielasi A, Latib A, Naganuma T, et al. Early results following everolimuseluting bioresorbable vascular scaffold implantation for the treatment of in-stent restenosis. Int J Cardiol. 2014;173(3):513-514.

78. Ishibashi Y, Nakatani S, Onuma Y. Definite and probable bioresorbable scaffold thrombosis in stable and ACS patients. EuroIntervention. Epub September 22, 2014.

79. Park S-J, Ahn J-M, Kim Y-H, et al. Trial of everolimus-eluting stents or bypass surgery for coronary disease. N Engl J Med. 2015;372(13): 1204-1212.

80. Bangalore S, Guo Y, Samadashvili Z, Blecker S, Xu J, Hannan EL. Everolimus-eluting stents or bypass surgery for multivessel coronary disease. N Engl J Med. 2015;372(13):1213-1222.

81. Dangas GD, Serruys PW, Kereiakes DJ, et al. Meta-analysis of everolimus-eluting versus paclitaxel-eluting stents in coronary artery disease: final 3-year results of the SPIRIT clinical trials program (Clinical evaluation of the Xience $\mathrm{V}$ everolimus eluting coronary stent system in the treatment of patients with De Novo Native Coronary Artery Lesions). JACC Cardiovasc Interv. 2013;6(9):914-922.
Medical Devices: Evidence and Research

\section{Publish your work in this journal}

Medical Devices: Evidence and Research is an international, peerreviewed, open access journal that focuses on the evidence, technology, research, and expert opinion supporting the use and application of medical devices in the diagnosis, treatment and management of clinical conditions and physiological processes. The identification of novel

\section{Dovepress}

devices and optimal use of existing devices which will lead to improved clinical outcomes and more effective patient management and safety is a key feature. The manuscript management system is completely online and includes a quick and fair peer-review system. Visit http://www. dovepress.com/testimonials.php to read real quotes from authors. 